\title{
Pre-clinical Positron Emission Tomography Reconstruction Algorithm Effect on Cu-64 ATSM Lesion Hypoxia
}

\author{
Pre-klinik Pozitron Emisyon Tomografisi Rekonstrüksiyon Algoritmasının Cu-64 ATSM \\ Lezyon Hipoksisi Üzerine Etkisi
}

\author{
Bal Sanghera1, Katie Wood2, Luke I Sonoda', Andrew Gogbashian', Gerry Lowe1, Andre Nunes', James Stirling1, \\ Chris Shepherd1, Gwen Beynon', Wai Lup Wong1 \\ IMount Vernon Hospital, Paul Strickland Scanner Centre, Northwood, UK \\ 2Royal Surrey County Hospital, Clinic of Oncology, Guildford, UK
}

\begin{abstract}
Objective: Application of distinct positron emission tomography (PET) scan reconstruction algorithms can lead to statistically significant differences in measuring lesion functional properties. We looked at the influence of two-dimensional filtered back projection (2D FBP), two-dimensional ordered subset expectation maximization (2D OSEM), three-dimensional ordered subset expectation maximization (3D OSEM) without 3D maximum a posteriori and with (3D OSEM MAP) on lesion hypoxia tracer uptake using a pre-clinical PET scanner.

Methods: Reconstructed images of a rodent tumor model bearing P22 carcinosarcoma injected with hypoxia tracer Copper64-Diacetyl-bis (N4-methylthiosemicarbazone) (i.e. Cu-64 ATSM) were analyzed at 10 minute intervals till 60 minute post injection. Lesion maximum standardized uptake values $\left(S U V_{\text {max }}\right)$ and $S U V_{\text {max }} /$ background $S U V_{\text {mean }}(T / B)$ were recorded and investigated after application of multiple algorithm and reconstruction parameters to assess their influence on Cu-64 ATSM measurements and associated trends over time.

Results: SUV $V_{\text {max }}$ exhibited convergence for OSEM reconstructions while ANOVA results showed a significant difference in $S_{\text {SUV }}$ or T/B between 2D FBP, 2D OSEM, 3D OSEM and 3D OSEM MAP reconstructions across all time frames. SUV and T/B were greatest in magnitude for 2D OSEM followed by 3D OSEM MAP, 3D OSEM and then 2D FBP at all time frames respectively. Similarly SUV $\mathrm{Vax}_{\max }$ and T/B standard deviations (SD) were lowest for 2D OSEM in comparison with other algorithms.

Conclusion: Significantly higher magnitude lesion SUV $V_{\max }$ and T/B combined with lower SD were observed using 2D OSEM reconstruction in comparison with 2D FBP, 3D OSEM and 3D OSEM MAP algorithms at all time frames. Results are consistent with other published studies however more specimens are required for full validation.
\end{abstract}

Keywords: Positron emission tomography scan, Cu-ATSM, hypoxia, animal, image reconstruction, image analysis

Öz

Amaç: Farklı pozitron emisyon tomografisi (PET) rekonstrüksiyon algoritmalarının uygulanması lezyonun fonksiyonel özelliklerinde istatistiksel olarak anlamlı farklılıklara neden olabilir. Bu çalışmada iki-boyutlu filtreli geri projeksiyon (2D FBP), iki-boyutlu düzenli subset expectation maksimizasyonu (2D OSEM), 3D maksimum a posteriori olmaksizın (3D OSEM) ve 3D maksimum a posteriori ile (3D OSEM MAP) üç-boyutlu düzenli subset expectation maksimizasyonu kullanımının pre-klinik bir PET tarayıcıs ile lezyon hipoksisini izleyen maddenin (tracer) tutulumu üzerine etkisi incelenmiştir.

Yöntem: P22 karsinosarkomlu bir kemirgen tümör modelinde hipoksi izleyen maddenin Copper-64-Diacetyl-bis (N4methylthiosemicarbazone) (Cu-64 ATSM) enjeksiyonu ile 60. dakikaya kadar her 10 dakikada bir elde edilen rekonstrükte görüntüler incelendi. Lezyonun maksimum standardize tutulum değeri $\left(S U V_{\text {max }}\right)$ ve $S U V_{\text {max }} / t_{\text {taban }} S_{U V} V_{\text {ortalama }}(T / B)$ değerleri

Address for Correspondence: Bal Sanghera MD, Mount Vernon Hospital, Paul Strickland Scanner Centre, Northwood, UK Phone: +90192 3844392 E-mail: bal.sanghera@nhs.net Received: 01.08.2015 Accepted: 17.09.2015 
kaydedildi, ve multipl algoritma ve rekonstrüksiyon parametresi uygulanmasından sonra bunların Cu-64 ATSM ölçümleri üzerindeki etkisi ve farklı zaman dilimlerindeki seyri araştırıldı.

Bulgular: SUV $V_{\max }$ OSEM rekonstrüksiyonları için konverjans gösterirken ANOVA sonuçları tüm zaman dilimlerinde 2D FBP,

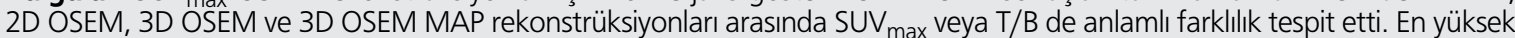
SUV $_{\max }$ ve T/B değerleri tüm zaman dilimlerinde 2D OSEM'de saptandı, bunu sırasıyla 3D OSEM MAP, 3D OSEM ve 2D FBP takip etti. Benzer şekilde SUV max $_{\text {ve }} \mathrm{T} / \mathrm{B}$ standart deviasyonları (SD) diğer algoritmalara kıyasla 2D OSEM'de en düşüktü.

Sonuç: 2D OSEM rekonstrüksiyonu ile 2D FBP, 3D OSEM ve 3D OSEM MAP algoritmalarına kıyasla tüm zaman dilimlerinde anlamlı olarak daha yüksek lezyon SUV $V_{\max }$ ve T/B ile birlikte daha düşük SD gözlemlendi. Sonuçlar daha önce yayınlanmış çalışmalarla uyumlu olmakla birlikte tam onaylama için daha fazla veri gerekmektedir.

Anahtar kelimeler: Pozitron emisyon tomografi taraması, Cu-ATSM, hipoksi, hayvan, görüntü oluşturma, görüntü analizi

\section{Introduction}

Tumors can often grow rapidly outstripping the blood supply they depend upon leaving regions with low oxygenation. Known as hypoxia (1), this phenomenon can reduce the efficacy of treatment regimens e.g. chemotherapy and radiotherapy due to diminished blood supply typical of malignant lesions (2). Methods to map (3) hypoxic regions in lesions are encouraged as these areas can be offered modified treatment regimens to increase overall therapeutic efficacy (4).

Positron emission tomography (PET) is a quantitative imaging modality using spatial and temporal distributions of radiolabelled molecules (tracers) to identify functional tissue disease processes and to monitor these during treatment (5). A distinct advantage is its ability to detect small levels of tracer with high sensitivity without upsetting biological processes that occur naturally. PET depends upon radioactive labels attached to ligands or molecules of functional importance. Clinically the most common of these is F-18 attached to a glucose analogue F-18 fluorodeoxyglucose (FDG) to image glucose metabolism as many cancer cells exhibit enhanced glycolysis (6). In this context, small bore animal PET scanners offer advantages of accurate quantitative scanning in oncological $(7,8)$ imaging applications leading to greater understanding of functional processes prior to potential translation to the clinic.

FDG PET has been applied to image hypoxia in cancer but other tracers are recommended (9) as glucose metabolism is considered a non-specific hypoxia marker. Copper-labeled ligands have shown promise in pre-clinical oncology imaging applications (10). Copper-64-Diacetylbis (N4-methylthiosemicarbazone) (Cu-64 ATSM) is considered as a more specific, hypoxia focused imaging agent with potential in radiotherapy treatment planning applications (11). Cu-64 ATSM yields relatively high tumor uptake, but in comparison with other hypoxia PET tracers, contradictory results and inconsistent correlation with immunohistochemistry hypoxia markers (12) are common. Besides variability driven by underlying biological processes, technological factors like image reconstruction algorithms also introduce uncertainty in SUV (13). As there is no optimal choice, algorithm selection can depend on requirements like quantitative accuracy, count-rate, maximising SUV or signal/noise $(S / N)(14)$. It is recognised that changing software default parameters within a particular algorithm influences SUV and lesion detectability $(15,16)$. Moreover, studies have been performed showing the effect of acquisition time on $\mathrm{S} / \mathrm{N}$ using different reconstruction algorithms (17). The significance of accurate PET image reconstruction and semi-quantitative analysis in oncology should not be overlooked. For example, comparison of various algorithms resulted in clinically different dose distributions for proposed treatment regimes in one cancer study (18).

In our study, we present the effects of applying different image reconstruction algorithms to scans acquired from a rat tumor model at 10 min intervals upto an hour post injection of CU-64 ATSM with a commercial pre-clinical PET scanner. Manufacturer supplied and widely used standard image reconstruction algorithms included 2D FBP, 2D OSEM, 3D OSEM and 3D OSEM MAP. In this setting, we compared the influence these image reconstruction algorithms make on SUV $V_{\max }$ and T/B measurements that are commonly used to characterise lesions in hypoxia studies. Associated trends observed in these values at 10 min intervals are discussed with recommendations included over their combined impact on measuring hypoxia.

\section{Materials and Methods}

Cu-64 ATSM was produced in the Clinical PET Centre at St Thomas's Hospital, London by a CTI RDS-112 cyclotron accelerating protons into a Ni-64 plated target, followed by subsequent separation and purification processes. This study was performed at a dedicated centre having considerable experience with P22 carcinosarcoma/BD9 rats whilst ensuring full regulatory compliance. Dynamic image data acquisition was initiated post injection of $35 \mathrm{MBq}$ Cu-64 ATSM using a MicroPET Focus 220 (Concorde microsystems incorporated). The scanner consisted of 48 detector rings with 504 LSO crystals per ring each crystal having dimensions $1.5 \mathrm{~mm} \times 1.5 \mathrm{~mm} \times 10 \mathrm{~mm}$ covering an axial field of view of approximately $7.7 \mathrm{~cm}$. Scans were acquired on a single bed position over the lesion with a threshold window between $350 \mathrm{keV}$ and $750 \mathrm{keV}$ and $6 \mathrm{~ns}$ 
timing window. Typical corrections were applied to validate efficacy of scans e.g. normalization, attenuation, arc, scatter etc. Transmission scans for attenuation correction over the area of interest were performed for 15 min using an integrated Co-57 source.

Hypoxia lesion characteristics were investigated on a single bed position following $10 \mathrm{~min}$ time frames acquired at 0-10 $\mathrm{min}, 10-20 \mathrm{~min}, 20-30 \mathrm{~min}, 30-40 \mathrm{~min}, 40-50 \mathrm{~min}$ and 50-60 min post injection of Cu-64 ATSM. Reconstructed scans consisted of (a) 2D FB, (b) 2D OSEM, (c) 3D OSEM and (d) 3D OSEM MAP algorithms using manufacturer supplied defaults. Reconstruction filters varied for analytical 2D FBP were Butterworth1 (b1), Butterworth2 (b2), Hamming, Hanning and with no filter for each time point investigated. All were performed at axial cutoff (Nyquist) 0.5 resulting in 30 distinct 2D FBP reconstructions.

Similarly, for iterative reconstruction 2D OSEM iterations (it) varied between 1, 2, 3, 4 and 5. For each iteration the following subsets (sub) were used 2, 4, 6, 8, 10, 16, 22 and 28 sub with Fourier rebinning employed resulting in 240 separate reconstructions. In the case of 3D OSEM 1, 2, 3, 4 and 5 it were employed with 9 sub for each time point investigated resulting in 30 measurements. In the case of 3D OSEM MAP 2 it and 9 sub was employed for the OSEM and $0,2,4,6,8,10,12,14,16$ and 18 it for the MAP component; providing 60 reconstructions at different time points with a target FWHM of $1.5 \mathrm{~mm}$.

These different parameters were used to study the effect of reconstruction algorithm settings on pre-clinical Cu-64 ATSM lesion hypoxia SUV $V_{\max }$ and T/B for each $10 \mathrm{~min}$ time frame investigated. The same lesion or background defining volume of interest (VOI) was employed in the same location for all respective reconstructions to minimize variation arising from placement, Figure 1.

PSPP statistical software (19) was employed using oneway analysis of variance (ANOVA) with least significant difference (LSD) post hoc test to establish if differences between mean SUV max $_{\text {acquired using different }}$ reconstructions methods for the same time frame were of statistical significance. This process was also applied to mean T/B again acquired using different reconstructions methods for the same respective time frame.

\section{Results}

\section{SUV $_{\text {max }}$ Convergence}

Figure 2 depicts lesion SUV $\max$ measured using 2D OSEM reconstruction against the product of iterations and sub for different time frames. $S V_{\max }$ were all found to approximate to a plateau at time points investigated endorsing convergence of 2D OSEM algorithm used. Figures 3 and 4 further support $S_{\text {max }}$ convergence for 3D OSEM and 3D OSEM MAP reconstructions, respectively.

Trends in variation of uptake measurements with reconstruction parameters are better characterized in box and whisker plots (depicting minimum, mean +/standard deviation (SD) and maximum) for SUV $V_{\max }$ Figure 5 respectively. The additional influence of scan timing on measured parameters at 0-10 $\mathrm{min}, 10-20 \mathrm{~min}, 20-30 \mathrm{~min}$, 30-40 $\mathrm{min}, 40-50 \mathrm{~min}$ and $50-60 \mathrm{~min}$ is also seen.

\section{SUV $_{\text {max }}$}

For individual reconstruction algorithms, mean intra SUV $_{\text {max }}$ was greatest in magnitude for 2D OSEM followed by 3D OSEM MAP, 3D OSEM and finally 2D FBP, Figure 5. This result was reflected at all acquisition times. Likewise for individual reconstruction algorithm intra SD of uptake measurements was least in magnitude for 2D OSEM followed by 3D OSEM MAP, 3D OSEM and finally 2D FBP. Again, this trend was reflected across all time frames.

\section{SUV $_{\text {max }}$ One-Way ANOVA}

Statistical analysis revealed that mean SUV $\max$ acquired at $0-10$ min time frame exhibited a significant difference $(F(3.60)=4.7, p=0.0)$ between reconstruction groups 2D FBP, 2D OSEM, 3D OSEM and 3D OSEM MAP. This result was repeated at $10-20 \mathrm{~min}(F(3.60)=4.12, p=0.0), 20$ $30 \min (F(3.60)=2.81, p=0.0), 30-40 \min (F(3 ., 60)=6.67$, $\mathrm{p}=0.0), \quad 40-50 \mathrm{~min}(\mathrm{~F}(3.60)=6.32, \mathrm{p}=0.0)$ and $50-60$ $\min (F(3.60)=7.2, p=0.0)$. It can be seen in Table 1 that reconstruction groups display significant differences in mean $S U V_{\text {max }}$ within each respective time frame besides 2D FBP with 3D OSEM. It is observed the magnitude of mean SUV max for 3D OSEM >2D FBP at 0-10 min, 10-20 min, 20-30 $\mathrm{min}, 30-40 \mathrm{~min}$ and $50-60 \mathrm{~min}$ respectively. Non-statistically significant results are denoted with*.

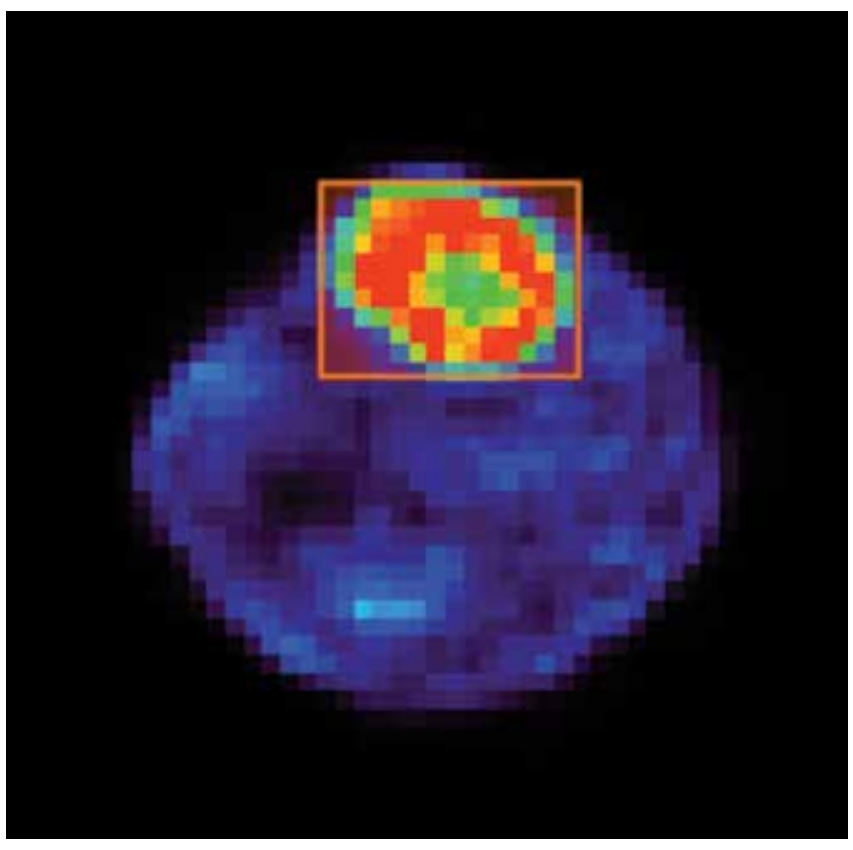

Figure 1. Image demonstrating rectangular volume of interest placement used to characterize the lesion imaged 


\section{T/B}

At each acquisition time, individual reconstruction algorithm's mean T/B was greatest in magnitude for 2D OSEM followed by 3D OSEM MAP, 3D OSEM and finally 2D FBP, Figure 6. Equally, individual reconstruction algorithm's intra SD for uptake measurements was least in magnitude for 2D OSEM followed by 3D OSEM MAP, 3D OSEM and finally 2D FBP across all time points.

\section{T/B One-Way ANOVA}

Statistical analysis revealed that mean T/B derived at 0-10 min time frame exhibited a significant difference

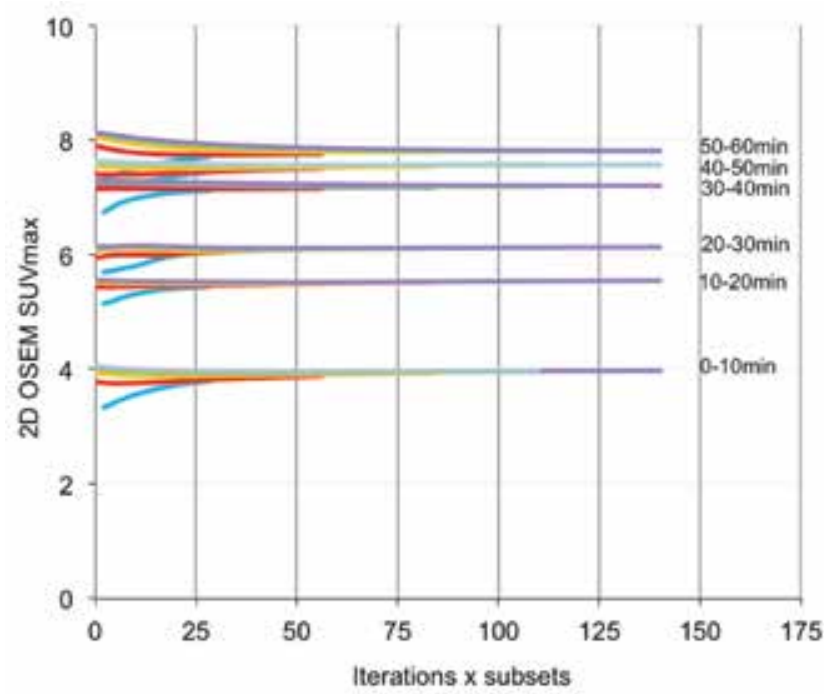

Figure 2. Two-dimensional ordered subset expectation maximization convergence for lesion SUV $\max$ at 0-10 min, 10-20 min, 20-30 min, 30-40 $\min , 40-50 \mathrm{~min}$ and 50-60 min post injection

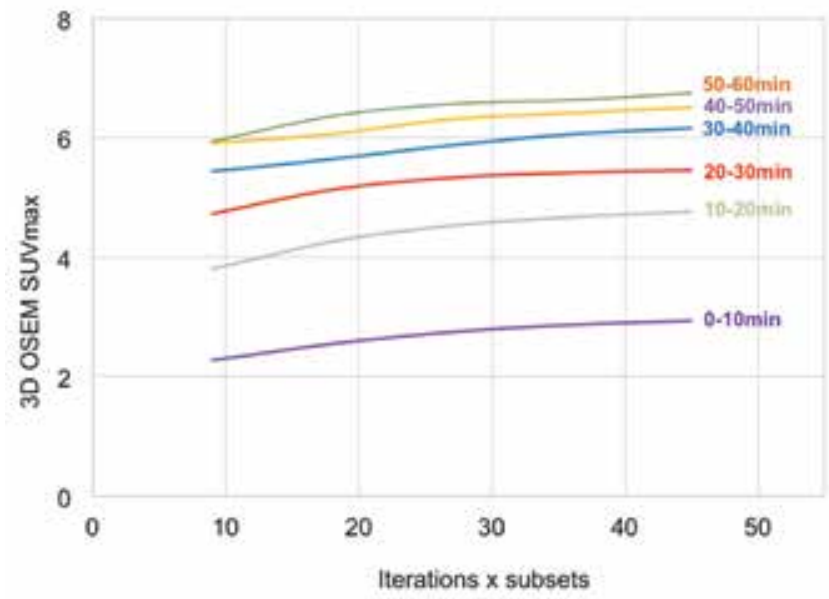

Figure 3. Three-dimensional ordered subset expectation maximization convergence with iteration for lesion SUV $V_{\max }$ at 0-10 min, 10-20 min, 20-30 $\mathrm{min}, 30-40 \mathrm{~min}, 40-50 \mathrm{~min}$ and 50-60 min post injection
$(F(3.60)=8.03, p=0.0)$ between reconstruction groups 2D FBP, 2D OSEM, 3D OSEM and 3D OSEM MAP. This result was repeated at 10-20 $\min (F(3.60)=9.36, p=0.0), 20-30$ $\min (F(3.60)=8.19, p=0.0), 30-40 \min (F(3.60)=19.85$, $p=0.0), 40-50 \min (F(3.60)=18.16, p=0.0)$ and $50-60 \mathrm{~min}$ $(F(3.60)=22.33, p=0.0)$.

It can be seen in Table 2 that reconstruction groups display significant differences in mean T/B within each respective time frame besides 3D OSEM with 3D OSEM MAP at 20-30 min and 40-50 min. It is observed the magnitude of mean T/B for 3D OSEM MAP $>3 D$ OSEM at 0-10 min, 10-20 min, 20-30 min, 30-40 min and 50-60 min respectively. Non-statistically significant results are denoted with*.

\section{Discussion}

Pre-clinical PET scanner studies provide an opportunity to investigate accurate, quantitative, functional properties of lesions in preparation of potential clinical trials. In this study we investigated the effect of available and widely used reconstruction algorithms on Cu-64 ATSM hypoxia characteristics of a rodent tumor rather than investigating general biochemical uptake mechanisms or phantom scan data. Furthermore, in relation to other animal tumors, this P22 model was more oxic, solid and relatively large, thereby more relevant to a human tumor model.

Additional reconstructions had to be performed retrospectively following relocation of the scanner, with associated dedicated software and hardware to another imaging centre. Siemens Imaging Oxford kindly assisted with supply of reconstruction software and default supplementary files necessary to perform these locally at our site. A networked Intel Pentium $4 \mathrm{CPU}, 3.4 \mathrm{GHz}, 1$

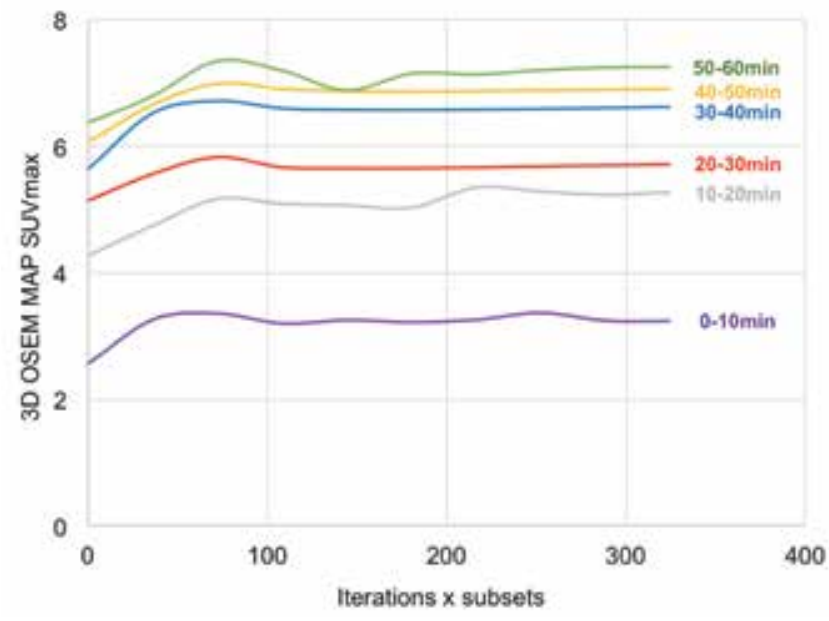

Figure 4. Three-dimensional ordered subset expectation maximization maximum a posteriori convergence with iteration for lesion $S U V_{\max }$ at 0-10 min, 10-20 min, 20-30 min, 30-40 min, 40-50 min and 50-60 min post injection 
GB RAM 80 GB hard drive PC running Windows XP 64 bit operating system was identified as a compatible machine and painstakingly configured to perform reconstructions. This platform enabled complex reconstruction e.g. 2D FBP, 2D OSEM 5 it 28 sub, 3D OSEM 5 it and 3D OSEM MAP 2 it 18 sub algorithms to be completed in approximately 10 min, $1 \mathrm{hr}, 44.5 \mathrm{hr}$ and $90 \mathrm{hr}$ respectively.

All reconstruction algorithms showed increased magnitude of mean $S U V_{\max }$ and mean $T / B$ with time frame measured, reflecting known uptake characteristics of $\mathrm{Cu}-64$ ATSM for hypoxia measurements (20), thus offering some level of assurance that reconstruction algorithms were functioning appropriately. In order to assist characterizing reconstruction effects using different algorithms, we identified general trends from $S U V_{\max }$ and $T / B$ results acquired at time frames specified. Figures 5 and 6 show a trend in mean value magnitudes of SUV $V_{\max }$ and $T / B$ where 2D OSEM >3D OSEM MAP >3D OSEM >2D FBP at different time frames. Similarly with measurements of SD for mean $S U V_{\max }$ and mean $T / B$, Figures 5 and 6 , we see a trend where 2D OSEM <3D OSEM or 3D OSEM MAP <2D FBP at different time frames.

Larger SD across reconstructions observed with FBP algorithm for mean SUV $\max$ and mean T/B may reflect limitations of this algorithm (13), arising from applying available defaults and possible low count-rate statistics. As expected for each respective time frame and within each respective reconstruction algorithm, mean $\mathrm{T} / \mathrm{B}$ $>$ corresponding mean $S U V_{\max }$ and the difference was statistically significant ( $p<0.0001$ in all cases) (21).

It may be argued amongst the reconstruction parameters available and consequently used with our imaging system that 2D OSEM potentially offers a good compromise for improved imaging. For all time frames investigated, 2D OSEM generated SUV $\max$ and T/B consistently demonstrated relatively large magnitude mean values and exhibited less SD in comparison with other reconstruction algorithms for parameters used. Our endorsement of 2D OSEM image reconstruction agrees with another similar study using a newer generation scanner (13).

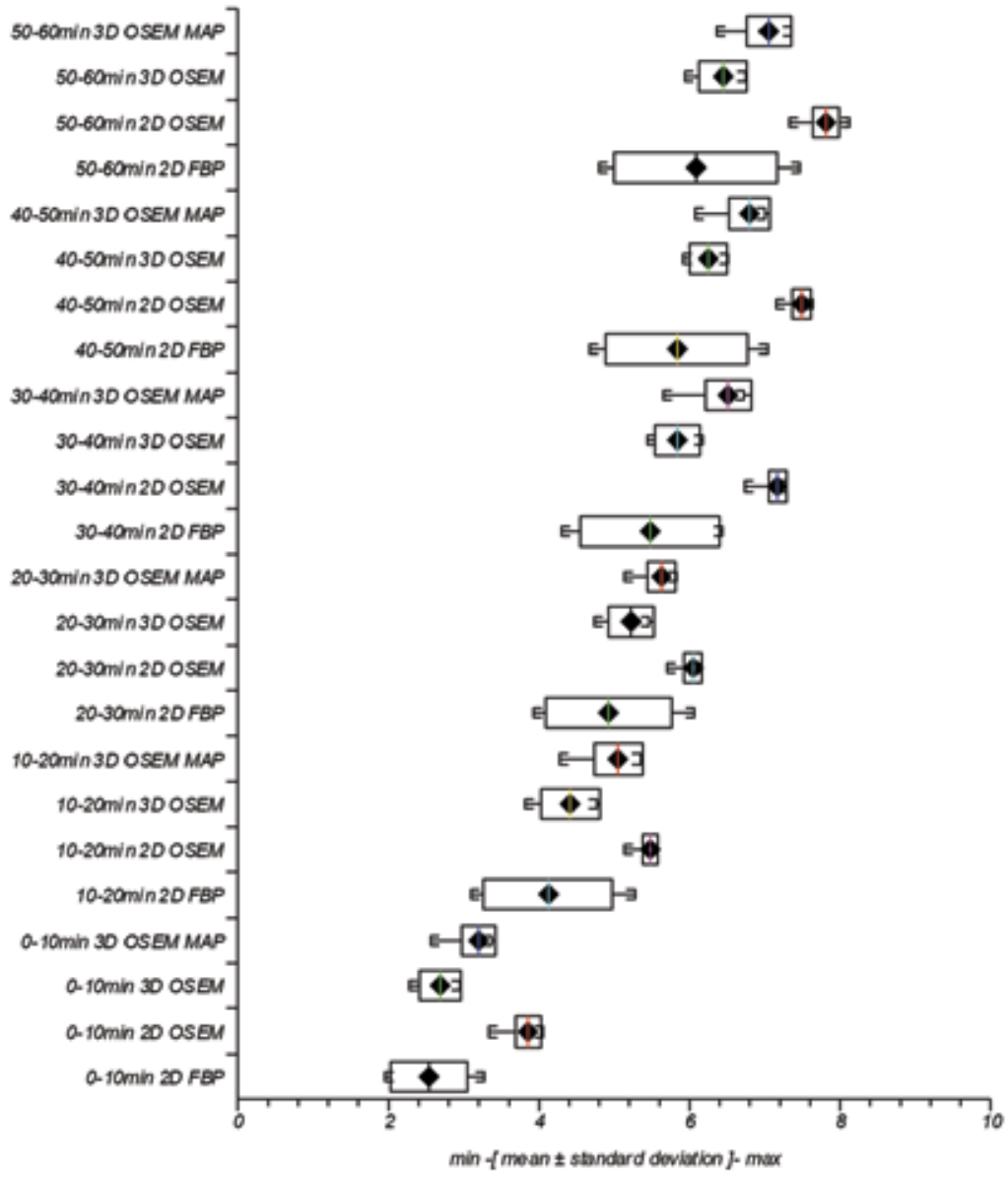

Figure 5. Variation in lesion SUVmax with two-dimensional filtered back projection, two-dimensional ordered subset expectation maximization, threedimensional ordered subset expectation maximization and maximum a posteriori with different reconstruction parameters and at different time frames 
Our aim was to look at differences introduced by multiple algorithms with various available default parameters and observe trends in SUV $V_{\max }$ and $T / B$ measurements often used to characterize lesions. Limitations to the study arose from lack of objective gold standard with which to compare results using different standard image reconstruction algorithms in the genuine rat tumor investigated. Furthermore, scans were reconstructed at specific time periods with data available from one sacrificed animal only. Hence, results presented should not be extrapolated beyond this remit without further studies. However, there is no reason to doubt that the outcome of this study is not representative of a rat P22 tumor model and results presented are supported by others (13).

\section{Conclusions}

Typical image reconstruction algorithms and parameters were compared for lesion SUV $\max$ or $T / B$ in 10 min time frames 0-10 $\mathrm{min}, 10-20 \mathrm{~min}, 20-30 \mathrm{~min}, 30-40 \mathrm{~min}$ and
50-60 min time points post injection following dynamic hypoxia scanning of a rat tumor with CU-64 ATSM. It was observed that 2D OSEM in comparison with 2D FBP, 3D OSEM and 3D OSEM MAP reconstructions represented the highest magnitude $S U V_{\max }$ and $T / B$, combined with the lowest SD respectively for the hypoxic lesion studied. Differences between reconstruction algorithms in the vast majority of cases were statistically significant at time points measured. More specimens are required for full validation though results are consistent with other published studies.

\section{Acknowledgement}

The authors would like to acknowledge the contributions of Will Hallett and Nick Keat from Imanova for their initial support and their contacts at Siemens. The huge efforts of Antje Schulte and Axel Weber from Siemens in faultfinding and supplying reconstruction software are very much appreciated. Finally support from the IT department in providing a workstation with the correct operating system and with networking matters greatly assisted the project.

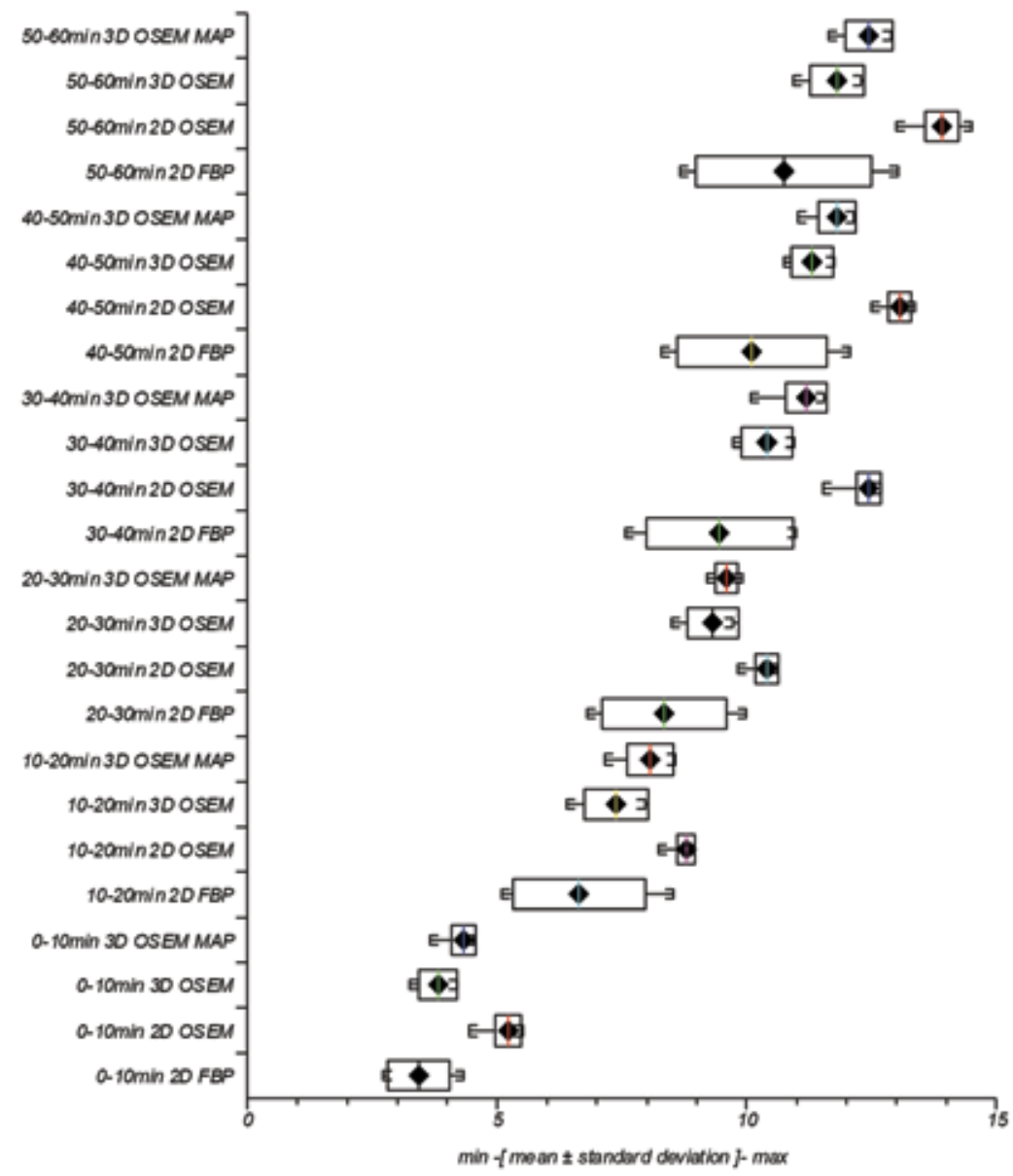

Figure 6. Variation in lesion T/B with two-dimensional filtered back projection, two-dimensional ordered subset expectation maximization, three-dimensional ordered subset expectation maximization and maximum a posteriori with different reconstruction parameters and at different time frames 


\section{Authorship Contributions}

Ethics Committee Approval: Relevant authorizations were received for this animal study, Informed Consent: Not required (animal study), Concept: Bal Sanghera, Katie Wood, Luke I Sonoda, Andrew Gogbashian, Gerry Lowe, Andre Nunes, James Stirling, Chris Shepherd, Gwen Beynon, Wai Lup Wong, Design: Bal Sanghera, Katie Wood, Data Collection or Processing: Bal Sanghera, Katie Wood, Analysis or Interpretation: Bal Sanghera, Katie Wood, Luke I Sonoda, Andrew Gogbashian, Gerry Lowe, Andre Nunes, James Stirling, Chris Shepherd, Gwen Beynon, Wai Lup Wong, Literature Search: Bal Sanghera, Katie Wood, Luke I Sonoda, Andrew Gogbashian, Gerry Lowe, Andre Nunes, James Stirling, Chris Shepherd, Gwen Beynon, Wai Lup Wong, Writing: Bal Sanghera, Katie Wood, Peer-review: Externally peer-reviewed, Conflict of Interest: No conflict of interest was declared by the authors, Financial Disclosure: The authors declared that this study has received no financial support.

\section{References}

1. Leach RM, Treacher DF. Oxygen transport-2. Tissue hypoxia. BMJ 1998;317:1370-1373.

2. Vaupel $P$, Mayer A. Hypoxia in cancer: significance and impact on clinical outcome. Cancer Metastasis Rev 2007;26:225-239.

3. Krohn KA, Link JM, Mason RP. Molecular imaging of hypoxia. J Nucl Med 2008;49 (Suppl 2):129-148.

4. Wilson WR, Hay MP. Targeting hypoxia in cancer therapy. Nat Rev Cancer 2011;11:393-410.

5. Carlier T, Bailly C. State-of-the-art and recent advances in quantification for therapeutic follow-up in oncology using PET. Front Med (Lausanne) 2015;2:18.

6. Warburg O. On the origin of cancer cells. Science 1956;123:309-314.

7. Yao R, Lecomte R, Crawford ES. Small-animal PET: what is it, and why do we need it? J Nucl Med Technol 2012;40:157-165.

8. Kuntner C, Stout D. Quantitative preclinical PET imaging: opportunities and challenges. Front Physics 2014. http://dx.doi.org/10.3389/ fphy.2014.00012.
9. Dierckx RA, Van de Wiele C. FDG uptake, a surrogate of tumour hypoxia? Eur J Nucl Med Mol Imaging 2008;35:1544-1549.

10. Niccoli Asabella A, Cascini GL, Altini C, Paparella D, Notaristefano A, Rubini G. The copper radioisotopes: a systematic review with special interest to 64Cu. Biomed Res Int 2014;2014:786463.

11. Clausen MM, Hansen $A E$, Lundemann $M$, Hollensen $C$, Pommer T, Munck Af Rosenschöld P, Kristensen AT, Kjær A, McEvoy FJ, Engelholm SA. Dose painting based on tumor uptake of Cu-ATSM and FDG: a comparative study. Radiat Oncol 2014;9:228.

12. Carlin S, Zhang H, Reese M, Ramos NN, Chen Q, Ricketts SA. A comparison of the imaging characteristics and microregional distribution of 4 hypoxia PET tracers. J Nucl Med 2014;55:515-521.

13. Yu AR, Kim JS, Kang H, Lim SM. Comparison of reconstruction methods and quantitative accuracy in Siemens Inveon PET scanner. J Inst 2015; doi:10.1088/1748-0221/10/04/P04001.

14. Thorwarth D, Mönnich D, Zips D. Methodological aspects on hypoxia PET acquisition and image processing. Q J Nucl Med Mol Imaging 2013;57:235-243.

15. Defrise $M$, Kinahan $P E$, Michel $C J$. Image reconstruction algorithms PET. In: Bailey DL, Townsend DW, Valk PE, Maisey MN (eds). Positron Emission Tomography: Basic Sciences. London, Springer-Verlag, 2005:63-91.

16. Schaefferkoetter J, Casey M, Townsend D, El Fakhri GE. Clinical impact of time-of-flight and point response modeling in PET reconstructions: a lesion detection study. Phys Med Biol 2013;58:1465-1478.

17. Morey AM, Kadrmas DJ. Effect of varying number of OSEM subsets on PET lesion detectability. J Nucl Med Technol 2013;41:268-273.

18. Knudtsen IS, van Elmpt W, Ollers M, Malinen E. Impact of PET reconstruction algorithm and threshold on dose painting of nonsmall cell lung cancer. Radiother Oncol 2014;113:210-214.

19. Plaff B, Darrington J, GNU PSPP. Version 0.8.4. http://www.gnu.org/ software/pspp/.

20. Bayly SR, King RC, Honess DJ, Barnard PJ, Betts HM, Holland JP, Hueting $\mathrm{R}$, Bonnitcha PD, Dilworth JR, Aigbirhio FI, Christlieb M. In vitro and in vivo evaluations of a hydrophilic 64Cu bis(thiosemicarbazonato)glucose conjugate for hypoxia imaging. J Nucl Med 2008;49:18621888.

21. Knight JC, Wuest M, Saad FA, Wang M, Chapman DW, Jans HS, Lapi SE, Kariuki BM, Amoroso AJ, Wuest F. Synthesis, characterisation and evaluation of a novel copper-64 complex with selective uptake in EMT-6 cells under hypoxic conditions. Dalton Trans 2013;42:1200512014. 